\title{
Genotype Variations and Association between PAI-1 Promoter Region (4G/5G and -844G/A) and Susceptibility to Acute Myocardial Infarction and Chronic Stable Angina
}

\author{
Sunil Kumar ${ }^{(D},{ }^{1}$ Amit Kumar Verma, ${ }^{2}$ Vinay Sagar, ${ }^{3}$ Ravi Ranjan, ${ }^{4}$ Rahul Sharma, \\ Preeti Tomar, ${ }^{4}$ Deepti Bhatt, ${ }^{2}$ Yamini Goyal, ${ }^{2}$ Mohammed A. Alsahli, ${ }^{5}$ \\ Ahmad Almatroudi $\left(\mathbb{D},{ }^{5}\right.$ Saleh A. Almatroodi, ${ }^{5}$ Arshad Husain Rahmani $\left(\mathbb{D},{ }^{5}\right.$ \\ Faris Alrumaihi, ${ }^{5}$ Khursheed Muzammil, ${ }^{6}$ Kapil Dev ${ }^{(D)},{ }^{2}$ Rakesh Yadav, ${ }^{7}$ and Renu Saxena ${ }^{4}$ \\ ${ }^{1}$ Department of Microbiology, Government Doon Medical College, Dehradun, India \\ ${ }^{2}$ Department of Biotechnology, JMI, New Delhi, India \\ ${ }^{3}$ Department of Internal Medicine, PGIMER, Chandigarh, India \\ ${ }^{4}$ Department of Hematology, AIIMS, New Delhi, India \\ ${ }^{5}$ Department of Medical Laboratories, College of Applied Medical Sciences, Qassim University, Buraidah, Saudi Arabia \\ ${ }^{6}$ Department of Public Health, College of Applied Medical Sciences, Khamis Mushayt, King Khalid University, Abha, \\ Saudi Arabia \\ ${ }^{7}$ Department of Cardiology, AIIMS, New Delhi, India
}

Correspondence should be addressed to Sunil Kumar; drsunilaiims@gmail.com

Received 8 February 2021; Revised 28 April 2021; Accepted 30 May 2021; Published 28 June 2021

Academic Editor: Mariantonietta Cicoira

Copyright (C) 2021 Sunil Kumar et al. This is an open access article distributed under the Creative Commons Attribution License, which permits unrestricted use, distribution, and reproduction in any medium, provided the original work is properly cited.

The present study aimed at investigating the $4 \mathrm{G} / 5 \mathrm{G}$ and $-844 \mathrm{G} / \mathrm{A}$ polymorphisms and plasma concentration of PAI- 1 in patients with acute myocardial infarction (AMI) and chronic stable angina (CSA) in Indian population. It included 100 patients with AMI and stable angina and 100 healthy controls. All study subjects were typed for two PAI polymorphisms (4G/5G and -844G/A) through PCR-RFLP and level of PAI through ELISA. The comparison of AMI and CSA independently with control in terms of PAI-1 level was statistically significant but not between AMI and CSA. The frequency of 4G/4G and 4G/5G genotype and 4G allele was significantly higher in AMI cases than in control and was found to increase the risk of AMI. There was a significant relationship between $4 \mathrm{G} / 5 \mathrm{G}$ polymorphism and AMI risk under the dominant and codominant genotype. The frequency of $4 \mathrm{G} / 4 \mathrm{G}$ genotype and $4 \mathrm{G}$ allele was significantly higher in CSA cases than in control group and increases the risk of CSA. There was no significant association between $4 \mathrm{G} / 5 \mathrm{G}$ polymorphism and CSA risk under recessive, dominant, and codominant models. The genotype and allelic frequencies difference between the cases (AMI and CSA) and control with regard to -844G/A polymorphisms were statistically nonsignificant. Also, we did not detect any significant association of -844G/A polymorphism with AMI and CSA in recessive, dominant, and codominant models. Along with the traditional risk factors, the $4 \mathrm{G} / 5 \mathrm{G}$ allele polymorphism is an independent risk factor for the development of AMI. The detection of $4 \mathrm{G} / 5 \mathrm{G}$ allele may therefore be helpful in primary prevention. Patients who carry the 4G/5G allele polymorphism have high concentrations of PAI-1, which might be involved in incidents leading to AMI. The present study for the first time revealed significant association of 4G/5G allele polymorphism with high risk of AMI in Indian population and will be helpful in identifying the genetic risk factors associated with AMI and CSA and for better management of diagnostic measures. 


\section{Introduction}

Atherothrombotic changes are one of the major causes of cardiovascular morbidity and mortality. Coronary artery disease (CAD) that encompasses chronic stable angina (CSA), unstable angina (USA), and acute myocardial infarction (AMI) has numerous known genetic and environmental risk factors. Risk factors that are well established include smoking, heavy alcohol consumption, hypertension, diabetes, family history, and dyslipidemia and their association with CAD is believed to be largely under genetic control $[1,2]$.

Plasminogen activator inhibitor-1 (PAI-1) is one of vital regulatory elements of fibrinolytic pathway. It inhibits both tissue and urokinase specific plasminogen inhibitor; thus its raised level seems to promote prothrombotic state and related vascular changes [3]. Several PAI-1 gene polymorphisms have been described in literature; however, only few of them alter the inhibitor level in plasma. A single guanosine deletion/insertion polymorphism (4G or $5 \mathrm{G}$ ) located in the promoter region of the PAI-1 gene at 675 base pair upstream from the transcription-starting site has a functional role in PAI-1 synthesis and expression [4]. The PAI-1 level is noted to be higher in $4 \mathrm{G}$ allele carrier as compared to $5 \mathrm{G}$ carrier, as both polymorphic alleles bind to transcription activator, whereas $5 \mathrm{G}$ also binds a repressor protein to an overlapping binding site [5]. PAI-1 4G/5G gene polymorphism is believed to unmask thrombotic phenotype in patients with underlying prothrombotic disorders in both arterial and venous beds such as protein S deficiency, factor $\mathrm{V}$ Leiden defect, and antiphospholipid antibody syndrome [6-8]. Numerous studies have already been conducted to evaluate the possible sequel of PAI-1 4G/5G gene polymorphism; nevertheless, they reported only conflicting results.

Similarly, there is another polymorphism with nucleotide substitution of guanine for adenine at 844 position results in altered gene expression and plasma PAI-1 levels, possibly by affecting the binding of nuclear proteins to the PAI-1 promoter. Studies assessing -844G/A polymorphisms and their role in prothrombotic states identified outcomes identical to $4 \mathrm{G} / 5 \mathrm{G}$ gene polymorphism.

The present study aimed to investigate the $4 \mathrm{G} / 5 \mathrm{G}$ and -844G/A polymorphisms and plasma concentration of PAI1 in patients with CAD, particularly in AMI and CSA, and its comparison with normal control subjects.

\section{Material and Methods}

2.1. Study Subjects. This study was conducted in the Department of Hematology, All India Institute of Medical Sciences, New Delhi, India, after obtaining the ethical clearance from the institutional board (Ref.No.IESC/T-252/ 03.06.2011) and written informed consent was collected from all patients and controls. We enrolled one hundred nonrelated consecutive AMI patients (male : female $=82: 18$; age range $=18$ to 75 years) and one hundred nonrelated consecutive SA patients $(\mathrm{M}: \mathrm{F}=82: 18$; age range $=18$ to 75 years) based on American College Cardiology/American
Heart Association (ACC/AHA) criteria. Patients exclusively of North-Indian origin were included in the study. Patients on oral anticoagulant or on any medication (antibiotics, aspirin, contraceptives, or steroids) were included in the study only if they were off the medication for a minimum period of two weeks (from the time of sampling). Patients with cancer, unstable angina, stroke, and hematological disorder, pediatric patients, and patients who had undergone surgery or had suffered trauma in the past 30 days were excluded from the study. Nonrelated sex and age matched as much as possible healthy individuals $(n=100)$ were also included in the study to serve as the disease-free control population. Controls were mainly hospital staffers, trainees, and unrelated healthy patient attendants. $10 \mathrm{ml}$ of blood sample was collected from all study participants in siliconized glass containers, containing 3.2\% sodium citrate solution. Plasma was isolated within $45 \mathrm{~min}$ of sampling and stored at $-70^{\circ} \mathrm{C}$ for further evaluation.

2.2. PAI-1 Genotyping. Genomic DNA was isolated from peripheral blood leucocytes by employing standard methods. Genotypic screening protocols for $4 \mathrm{G} / 5 \mathrm{G}$ were done through allele-specific PCR. The PCR reaction used an upstream control primer (5'- AAG CTT TTA CCA TGG TAA CCC CTG GT- $\left.3^{\prime}\right)$, an allele-specific primer $4 \mathrm{G}\left(5^{\prime}\right.$ GTC TGG ACA CGT GGG GA-3') or 5G (5'-GTC TGG ACA CGT GGGGG-3'), and a common downstream primer (5'-TGC AGC CAG CCA CGT GAT TGT CTA-3'). Two PCR reactions were run per a sample (one for $4 \mathrm{G}$ allele and the other for $5 \mathrm{G}$ allele); i.e., each reaction contained upstream primer, downstream primer, and one primer for $4 \mathrm{G}$ or 5G. The control upstream primer is used to verify the occurrence of DNA amplification. The PCR product was electrophoresed on $1.5 \%$ agarose gel stained with ethidium bromide. A $257 \mathrm{bp}$ control band resulted from the upstream and downstream primers. The $4 \mathrm{G}$ or $5 \mathrm{G}$ allele-specific primer and downstream primer produced $139 \mathrm{bp}$ fragment. Patients who showed amplification products with only $4 \mathrm{G}$ primers were $4 \mathrm{G} / 4 \mathrm{G}$, and those with only $5 \mathrm{G}$ primers were $5 \mathrm{G} / 5 \mathrm{G}$ and patients who had amplification products with both primers were $4 \mathrm{G} / 5 \mathrm{G}$. The gel for $4 \mathrm{G} / 5 \mathrm{G}$ polymorphism is shown in Figure 1.

The $-844 \mathrm{G} / \mathrm{A}$ polymorphism was detected by polymerase chain reaction and restriction fragment length polymorphism (PCR-RFLP), with the use of the following primers: forward, 5'-CAGGCTCCCACTGATTCTAC-3; and reverse, 5'-GAGGGCTCTCTTGTGTCAAC-3, amplified products were digested by XhoI and separated on $2 \%$ agarose gel. The $-844 \mathrm{G}$ allele was visualized as $314+146$ bp bands and the $-844 \mathrm{~A}$ allele was visualized as the $510 \mathrm{bp}$ fragment (Figure 2).

2.3. PAI-1 Antigen Assay. PAI-1 antigen was measured by a quantitative sandwich enzyme immunoassay technique (Assaypro LLC, St. Charles, USA) with a working range from 5 to $40 \mathrm{ng} / \mathrm{ml}$. ELISA was performed strictly according to the manufacturer's instructions provided in the kit manual. 


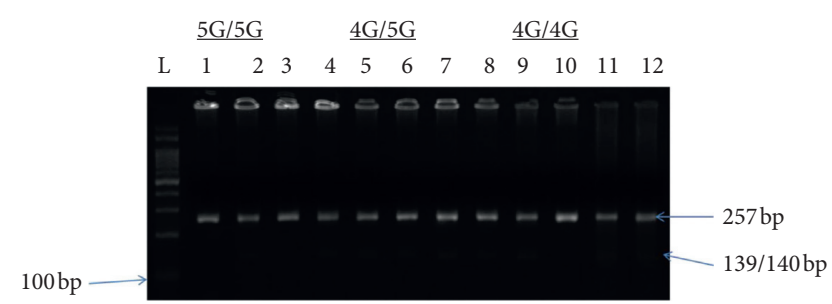

Figure 1: Amplified product of the 4G/5G polymorphism. L $100 \mathrm{bp}$ ladder, lanes 1 to 4 for $5 \mathrm{G}$ allele, lanes 9 and 10 for $4 \mathrm{G}$ allele, and lanes $5,6,7,8,11$, and 12 for $4 \mathrm{G} / 5 \mathrm{G}$ heterozygous allele.

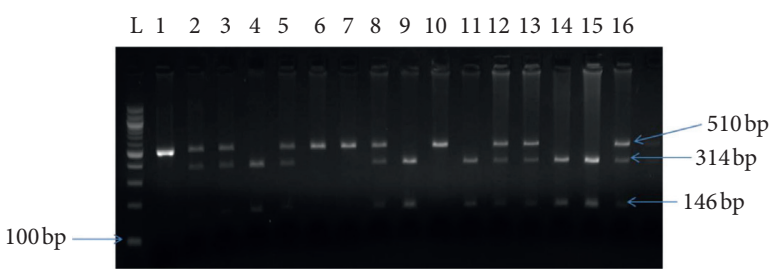

FIgURe 2: Amplified product of the $-844 \mathrm{G} / \mathrm{A}$ polymorphism through a PCR-RFLP. L: 100 bp ladder, lanes 1,6 , 7, and 10 homozygous mutant, lanes $2,3,5,8,12,13$, and 16: heterozygous, and lanes 4, 9, 11, 14, and 15: homozygous normal.

2.4. Statistical Analysis. Statistical analysis was performed using SPSS version 14.0 software programme. The variables between patients and controls were compared using Student's $t$ test and Chi square test. Data was presented as mean \pm SD or as percent of patients. Chi-square test was used for comparing genotype and allele frequencies for statistical significance between patients and controls. Odds ratios (ORs) with corresponding 95\% confidence intervals (CIs) were determined to assess the strength of association of $4 \mathrm{G} / 5 \mathrm{G}$ and $-844 \mathrm{G} / \mathrm{A}$ polymorphism with $\mathrm{AMI}$ and CSA risk. "p" values below 0.05 were considered significant.

\section{Results}

3.1. Clinical Characteristics of Cases (AMI and CSA) and Controls. The present study has average age $55.99 \pm 10.33$ years in AMI, $56.38 \pm 10.55$ years in CSA, and $52.07 \pm 14.44$ years in control group (Tables 1 and 2). A total of hundred cases were included in each group. Eighty-two percent were male in both AMI and CSA and $80 \%$ in control group. The presence of smoking was statistically significant in AMI and CSA patients as compared to controls $(p<0.05)$; however, situation was not the same in tobacco chewers $(p=0.068)$. Alcohol consumption was significantly higher in individuals who suffered AMI and CSA in contrast to control subjects $(p<0.05)$. Family history of CAD has been detected in $21 \%$ and $23 \%$ of AMI and CSA cases, respectively.

Comparison among the groups with regard to HDL level was statistically significant $(p<0.05)$, reflecting in the same way between AMI and control as well as between CSA and controls $(p<0.05)$. Similarly, the differences in LDL level between AMI $(109.49 \pm 4.78 \mathrm{mg} / \mathrm{dl})$ and controls $(99.96 \pm 3.22 \mathrm{mg} / \mathrm{dl})$ and CSA $(109.84 \pm 5.19 \mathrm{mg} / \mathrm{dl})$ and control were statistically significant $(p<0.05)$. In contrast, it is not true between AMI and CSA ( $p=1.00)$. BMI difference was statistically significant between CSA $(23.95 \pm 3.97 \mathrm{~kg} /$ $\left.\mathrm{m}^{2}\right)$ and controls $\left(22.39 \pm 3.92 \mathrm{~kg} / \mathrm{m}^{2}\right)$ with $p=0.012$. On the contrary, BMI difference between AMI $(23.60 \pm 3.53 \mathrm{~kg} /$ $\mathrm{dl})$ and controls and with CSA was not statistically significant ( $p=0.076$ and 1.0 , respectively). With regard to PAI level, it is highest in case of CSA $(30.04 \pm 8.32 \mathrm{ngm} / \mathrm{ml})$ followed by AMI $(28.62 \pm 8.57 \mathrm{ngm} / \mathrm{ml})$ and control $(22.93 \pm 7.22 \mathrm{ngm} / \mathrm{ml})$. The differences among these three groups were statistically significant $(p<0.05)$. In the same way, the comparison of AMI and CSA independently with control in terms of PAI-1 level was also statistically significant $(p<0.05)$ but not between AMI and CSA $(p<0.642)$.

\subsection{Association of $4 G / 5 G$ Polymorphism with Cases (AMI and} CSA). The distribution of genotype and allelic frequency for $4 \mathrm{G} / 5 \mathrm{G}$ polymorphism in AMI cases and control are summarized in Table 3. With reference to $5 \mathrm{G} / 5 \mathrm{G}$ genotype, frequency of $4 \mathrm{G} / 4 \mathrm{G}$ and $4 \mathrm{G} / 5 \mathrm{G}$ genotype was significantly higher in AMI cases than in control group and was found to increase the risk of AMI (OR, 6.51; 95\%CI, 2.67-15.8; $p<0.0001$ for $4 \mathrm{G} / 4 \mathrm{G}$; and $\mathrm{OR}, 6.52$; $95 \% \mathrm{CI}, 2.92-14.5$; $p<0.0001$ for $4 \mathrm{G} / 5 \mathrm{G}$, Table 3 ). The statistical analysis of observed genotypic frequencies showed significant association $(p<0.0001)$. The frequency of $4 \mathrm{G}$ allele was significantly higher in AMI cases than in controls (60\% vs. $39 \%$, respectively). Compared to $5 \mathrm{G}$ allele, the $4 \mathrm{G}$ allele significantly increases the risk of AMI (OR, 2.34; 95\% CI, $1.57-3.50 ; p<0.0001)$. We observed significant relationship between $4 \mathrm{G} / 5 \mathrm{G}$ polymorphism and AMI risk under the dominant $(\mathrm{OR}=6.51 ; 95 \% \mathrm{CI}: 3.03-13.9 ; p<0.0001)$ and codominant genotype (OR, 2.34; 95\% CI: 1.33-4.14; $p$-0.003), whereas there is no significant relationship under the recessive model (OR, 1.79; 95\% CI: 0.94-3.43; p-0.076).

The distributions of $4 \mathrm{G} / 4 \mathrm{G}, 4 \mathrm{G} / 5 \mathrm{G}$, and $5 \mathrm{G} / 5 \mathrm{G}$ genotypes were $32 \%, 36 \%$, and $32 \%$ in CSA cases and $20 \%, 38 \%$, and $42 \%$ in controls, respectively (Table 4 ). The statistical analysis of observed genotypic frequencies did not show significant difference $(p-0.1240)$. With reference to $5 \mathrm{G} / 5 \mathrm{G}$ genotype, $4 \mathrm{G} / 4 \mathrm{G}$ genotype was significantly higher in CSA cases than in control group and increases the risk of CSA (OR, 2.10; 95\%CI, 1.01-4.33; p-0.044, Table 4). We did not find any significant association of $4 \mathrm{G} / 5 \mathrm{G}$ polymorphism with CSA in recessive, dominant, and codominant models.

Additionally, we also found that the genotype frequency difference between AMI and CSA cases was statistically significant ( $p$-0.0001, Table 5).

3.3. Association of -844G/A Polymorphism with Cases (AMI and CSA). The distributions of genotype and allelic frequency for $-844 \mathrm{G} / \mathrm{A}$ polymorphism in AMI and control, CSA and control, AMI and CSA are listed in Tables 6-8, respectively.

The genotype frequencies for GG, GA, and AA in AMI cases vs. control were $20 \%, 56 \%$, and $24 \%$ and $24 \%, 54 \%$, and $22 \%$, respectively (Table 6 ). The genotype frequencies for $\mathrm{GG}, \mathrm{GA}$, and $\mathrm{AA}$ in the CSA cases were $18 \%, 54 \%$, and 
TABLE 1: Clinical characteristics of patients and controls.

\begin{tabular}{|c|c|c|c|c|}
\hline Characteristic & Group I (AMI) $(n=100)$ & Group II (CSA) $(n=100)$ & Group III (control) $(n=100)$ & $p$ value \\
\hline Age (years) & $55.99 \pm 10.33$ & $56.38 \pm 10.55$ & $52.07 \pm 14.44$ & \\
\hline Gender \% & & & & 0.947 \\
\hline Male & 82 & 82 & 80 & \\
\hline Female & 18 & 18 & 20 & \\
\hline Hypertension \% & 54 & 49 & 0 & 0.572 \\
\hline Diabetes \% & 24 & 37 & 0 & 0.065 \\
\hline Smoker \% & 36 & 41 & 11 & $<0.05$ \\
\hline Alcoholic \% & 26 & 26 & 7 & $<0.05$ \\
\hline Food habits $\%$ & & & & 0.029 \\
\hline Vegetarian & 39 & 53 & 57 & \\
\hline Nonvegetarian & 61 & 47 & 43 & \\
\hline Family history \% & 21 & 23 & 0 & 0.865 \\
\hline Total cholesterol(mg/dl) & $168.1 \pm 4.02$ & $169.59 \pm 3.80$ & $163.9 \pm 3.98$ & 0.836 \\
\hline Total HDL(mg/dl) & $30.18 \pm 2.61$ & $30.55 \pm 2.74$ & $41.31 \pm 2.59$ & 0.826 \\
\hline Total LDL(mg/dl) & $109.49 \pm 4.78$ & $109.84 \pm 5.19$ & $99.96 \pm 3.22$ & $<0.005$ \\
\hline BMI & $23.60 \pm 3.53$ & $23.97 \pm 3.97$ & $22.39 \pm 3.91$ & 0.452 \\
\hline PAI-1 antigen (ng/ml) & $28.62 \pm 8.57$ & $30.04 \pm 8.32$ & $22.93 \pm 7.22$ & 0.199 \\
\hline
\end{tabular}

Data presented as mean \pm SD except gender, hypertension, diabetes, smoker, alcoholic, food habits, and family history. ${ }^{*}$ Significant at $p<0.05$. BMI: body mass index; HDL: high density lipoprotein; LDL: low density lipoprotein; PAI: plasminogen activator inhibitor-1.

TABle 2: PAI level (ng/nl) in diabetic and nondiabetic cases.

\begin{tabular}{|c|c|c|c|c|c|c|c|}
\hline \multirow{2}{*}{ Group } & \multicolumn{3}{|c|}{ Diabetic } & \multicolumn{3}{|c|}{ Nondiabetic } & \multirow{2}{*}{$p$ value } \\
\hline & $N$ & Mean (SD) & PAI level (ng/ml) & $N$ & Mean (SD) & PAI level (ng/ml) & \\
\hline Group I (AMI) (100) & 24 & $33.75(7.93)$ & 32.5 & 76 & $27(8.16)$ & 27.5 & $<0.05$ \\
\hline Group II (CSA) (100) & 37 & $35.62(6.67)$ & 37 & 63 & $26.7(7.43)$ & 27 & $<0.05$ \\
\hline Group III (control) (100) & 0 & 0 & 0 & 100 & $22.9(7.21)$ & 25 & $<0.05$ \\
\hline
\end{tabular}

PAI: plasminogen activator inhibitor-1.

TABLE 3: Distribution of genotype and allelic frequency and association analysis of 4G/5G polymorphism with AMI cases under different genetic models.

\begin{tabular}{|c|c|c|c|c|c|}
\hline \multicolumn{2}{|c|}{ Genotype/allele } & Group I (AMI) $(n=100)$ & Group III (control) $(n=100)$ & Odds ratio $(95 \% \mathrm{CI})$ & $p$ value \\
\hline \multicolumn{2}{|c|}{$4 \mathrm{G} / 4 \mathrm{G}$} & $31(31 \%)$ & $20(20 \%)$ & $6.51(2.67-15.8)$ & $<0.0001^{*}$ \\
\hline \multicolumn{2}{|c|}{$4 \mathrm{G} / 5 \mathrm{G}$} & $59(59 \%)$ & $38(38 \%)$ & $6.52(2.92-14.5)$ & $<0.0001^{*}$ \\
\hline \multicolumn{2}{|c|}{$5 \mathrm{G} / 5 \mathrm{G}$} & $10(10 \%)$ & $42(42 \%)$ & Ref & Ref \\
\hline \multirow{3}{*}{ Recessive model } & & $p$ va & $e<0.0001$ & & \\
\hline & $4 \mathrm{G} / 4 \mathrm{G}$ & 31 & 20 & $1.79(0.94-3.43)$ & 0.076 \\
\hline & $4 \mathrm{G} / 5 \mathrm{G}+5 \mathrm{G} / 5 \mathrm{G}$ & 69 & 80 & & \\
\hline \multirow[t]{2}{*}{ Dominant model } & $4 \mathrm{G} / 5 \mathrm{G}+4 \mathrm{G} / 4 \mathrm{G}$ & 90 & 58 & $6.51(3.03-13.9)$ & $<0.0001^{*}$ \\
\hline & $5 \mathrm{G} / 5 \mathrm{G}$ & 10 & 42 & & \\
\hline Codominant model & $\begin{array}{c}4 G / 5 G \\
5 G / 5 G+4 G / 4 G\end{array}$ & 59 & 38 & $2.34(1.33-4.14)$ & $0.003^{*}$ \\
\hline \multicolumn{6}{|l|}{ Allele } \\
\hline \multicolumn{2}{|c|}{$4 \mathrm{G}$} & $120(60 \%)$ & $78(39 \%)$ & \multirow{2}{*}{$2.34(1.57-3.50)$} & \multirow{2}{*}{$<0.0001^{*}$} \\
\hline \multicolumn{2}{|c|}{$5 \mathrm{G}$} & $80(40 \%)$ & $122(61 \%)$ & & \\
\hline
\end{tabular}

OR: odds ratio, CI: confidence interval, and $n$ : number in sample. ${ }^{*}$ Significant at $p<0.005$.

$28 \%$, while in the controls they were $24 \%, 54 \%$, and $22 \%$, respectively (Table 7 ). The genotype frequencies difference between AMI cases and control, CSA cases and control, AMI and CSA cases were statistically nonsignificant ( $p$-0.783; $p$-0.454; $p$-0.798, respectively). Similarly, there was no significant difference in allele frequencies between AMI cases and control; CSA cases and control ( $p-0.548$; $p-0.230$, respectively) (Table 8 ). We did not find any significant association of $-844 \mathrm{G} / \mathrm{A}$ polymorphism with
AMI and CSA in recessive, dominant, and codominant models.

3.4. Association of $4 G / 5 G$ and $-844 G / A$ Polymorphisms with PAI-1 Level in Cases (AMI and CSA) and Controls. The 4G/ $5 \mathrm{G}$ polymorphisms and $-844 \mathrm{G} / \mathrm{A}$ polymorphisms were significantly associated with increased PAI-1 levels with $4 \mathrm{G} /$ $4 \mathrm{G}(p-0.019), 4 \mathrm{G} / 5 \mathrm{G}(p-0.001)$ and GA $(p-0.0009)$ and AA 
TABLE 4: Distribution of genotype and allelic frequency and association analysis of 4G/5G polymorphism with CSA under different genetic models.

\begin{tabular}{|c|c|c|c|c|c|}
\hline \multicolumn{2}{|c|}{ Genotype/allele } & Group II (CSA) $(n=100)$ & Group III (control) $(n=100)$ & Odds ratio $(95 \% \mathrm{CI})$ & $p$ value \\
\hline \multicolumn{2}{|c|}{$4 \mathrm{G} / 4 \mathrm{G}$} & $32(32 \%)$ & $20(20 \%)$ & $2.10(1.01-4.33)$ & $0.044^{*}$ \\
\hline \multicolumn{2}{|c|}{$4 \mathrm{G} / 5 \mathrm{G}$} & $36(36 \%)$ & $38(38 \%)$ & $1.24(0.65-2.37)$ & 0.509 \\
\hline \multicolumn{2}{|c|}{$5 \mathrm{G} / 5 \mathrm{G}$} & $32(32 \%)$ & $42(42 \%)$ & Ref & Ref \\
\hline \multicolumn{6}{|c|}{$P$ value -0.1240} \\
\hline \multirow{2}{*}{ Recessive model } & $4 \mathrm{G} / 4 \mathrm{G}$ & 32 & 20 & $188(0.98-3.58)$ & 0.054 \\
\hline & $4 \mathrm{G} / 5 \mathrm{G}+5 \mathrm{G} / 5 \mathrm{G}$ & 68 & 80 & $1.88(0.98-3.58)$ & \\
\hline \multirow{2}{*}{ Dominant model } & $4 \mathrm{G} / 5 \mathrm{G}+4 \mathrm{G} / 4 \mathrm{G}$ & 68 & 58 & $153(086-274)$ & 0.144 \\
\hline & $5 \mathrm{G} / 5 \mathrm{G}$ & 32 & 42 & $1.53(0.86-2.14)$ & 0.144 \\
\hline \multirow{2}{*}{ Codominant model } & $4 \mathrm{G} / 5 \mathrm{G}$ & 36 & 38 & & 0769 \\
\hline & $5 \mathrm{G} / 5 \mathrm{G}+4 \mathrm{G} / 4 \mathrm{G}$ & 64 & 62 & $0.91(0.51-1.62)$ & 0.169 \\
\hline \multicolumn{6}{|l|}{ Allele } \\
\hline \multicolumn{2}{|c|}{$4 \mathrm{G}$} & $100(50 \%)$ & $78(39 \%)$ & \multirow{2}{*}{$1.56(1.05-2.32)$} & \multirow{2}{*}{$0.027^{*}$} \\
\hline \multicolumn{2}{|c|}{$5 \mathrm{G}$} & $100(50 \%)$ & $122(61 \%)$ & & \\
\hline
\end{tabular}

OR: odds ratio, CI: confidence interval, and $n$ : number in sample. ${ }^{*}$ Significant at $p<0.05$.

TABLe 5: Genotypic distribution of 4G/5G polymorphism for AMI and CSA cases.

\begin{tabular}{|c|c|c|c|}
\hline Genotype & Group I (AMI) $(n=100)$ & Group II (CSA) $(n=100)$ & $p$ value \\
\hline $4 \mathrm{G} / 4 \mathrm{G}$ & $31(31 \%)$ & $32(32 \%)$ & \\
\hline $4 \mathrm{G} / 5 \mathrm{G}$ & $59(59 \%)$ & $36(36 \%)$ & $0.0001^{*}$ \\
\hline $5 \mathrm{G} / 5 \mathrm{G}$ & $10(10 \%)$ & $32(32 \%)$ & \\
\hline
\end{tabular}

* Significant at $p<0.05$.

TABLE 6: Distribution of genotype and allelic frequency and association analysis of -844G/A polymorphism with AMI under different genetic models.

\begin{tabular}{|c|c|c|c|c|c|}
\hline \multicolumn{2}{|c|}{ Genotype/allele } & Group I (AMI) $(n=100)$ & Group III (Control) $(n=100)$ & Odds ratio $(95 \% \mathrm{CI})$ & $p$ value \\
\hline \multicolumn{2}{|l|}{ GG } & $20(20 \%)$ & $24(24 \%)$ & Ref & Ref \\
\hline \multicolumn{2}{|l|}{ GA } & $56(56 \%)$ & $54(54 \%)$ & $1.24(0.61-2.50)$ & 0.541 \\
\hline \multicolumn{2}{|l|}{ AA } & $24(24 \%)$ & $22(22 \%)$ & $1.30(0.57-2.99)$ & 0.524 \\
\hline \multirow{3}{*}{ Recessive model } & & $p \mathrm{v}$ & $e-0.783$ & & \\
\hline & AA & 24 & 22 & \multirow{2}{*}{$1.11(0.57-2.16)$} & \multirow{2}{*}{0.736} \\
\hline & $\mathrm{GA}+\mathrm{GG}$ & 76 & 78 & & \\
\hline \multirow{2}{*}{ Dominant model } & $\mathrm{GA}+\mathrm{AA}$ & 80 & 76 & \multirow{2}{*}{$1.26(0.64-2.47)$} & \multirow{2}{*}{0.495} \\
\hline & GG & 20 & 24 & & \\
\hline \multirow{2}{*}{ Codominant model } & GA & 56 & 54 & \multirow{2}{*}{$1.08(0.62-1.89)$} & \multirow{2}{*}{0.776} \\
\hline & $\mathrm{GG}+\mathrm{AA}$ & 44 & 46 & & \\
\hline \multicolumn{6}{|l|}{ Allele } \\
\hline G & & $96(48 \%)$ & $102(51 \%)$ & \multirow{2}{*}{$1.12(0.76-1.66)$} & \multirow{2}{*}{0.548} \\
\hline A & & $104(52 \%)$ & $98(49 \%)$ & & \\
\hline
\end{tabular}

OR: odds ratio, CI: confidence interval, and $n$ : number in sample. ${ }^{*}$ Significant at $p<0.05$.

( $p$-0.022) genotypes, respectively, in AMI cases verses controls (Table 9). Likewise, elevated PAI-1 levels were significantly associated with the $4 \mathrm{G} / 4 \mathrm{G}(0.003)$ and $4 \mathrm{G} / 5 \mathrm{G}$ (0.0001) genotypes of $4 \mathrm{G} / 5 \mathrm{G}$ polymorphism and $\mathrm{GA}$ $(p<0.0001)$ and AA $(p-0.003)$ genotypes of $-844 \mathrm{G} / \mathrm{A}$ polymorphism in CSA cases versus control group (Table 10).

\section{Discussion}

The present study was conducted to ascertain the role of PAI-1 gene polymorphisms in the occurrence of coronary artery diseases including AMI and CSA in North-Indian population. We particularly concentrated on PAI-1 4G/5G and -844G/A polymorphisms, plasma PAI-1 levels, and their influence on development of thrombotic complications and stenosing lesions such as AMI and CSA, respectively.

Diet has significant effects on mortality due to ischemic heart disease. Various studies showed significantly reduced risk and mortality due to ischemic heart disease in individuals consuming vegetarian diet and it may be largely due to lower cholesterol concentrations in vegetarians than in nonvegetarians and due in part to other mechanisms such as reduced oxidation of LDL cholesterol and blood clotting $[9,10]$. Similar to these studies, our cohort also showed significantly increased risk of AMI in nonvegetarians; on the contrary, the incidence of CSA did not increase in nonvegetarians. Hypertension and diabetes are well-known associations with the occurrence of $\mathrm{CAD}$; however, we failed 
TABLE 7: Distribution of genotype and allelic frequency and association analysis of -844G/A polymorphism with CSA under different genetic models.

\begin{tabular}{|c|c|c|c|c|c|}
\hline \multicolumn{2}{|c|}{ Genotype/allele } & Group II (CSA) $(n=100)$ & Group III (control) $(n=100)$ & Odds ratio $(95 \% \mathrm{CI})$ & $p$ value \\
\hline \multicolumn{2}{|l|}{ GG } & $18(18 \%)$ & $24(24 \%)$ & Ref & Ref \\
\hline \multicolumn{2}{|l|}{ GA } & $54(54 \%)$ & $54(54 \%)$ & $1.33(0.65-2.73)$ & 0.432 \\
\hline \multirow{2}{*}{\multicolumn{2}{|c|}{$\mathrm{AA}$}} & $28(28 \%)$ & $22(22 \%)$ & $1.69(0.74-3.88)$ & 0.210 \\
\hline & & $p \mathrm{v}$ & e 0.454 & & \\
\hline \multirow{2}{*}{ Recessive model } & AA & 28 & 22 & \multirow{2}{*}{$1.37(0.72-2.62)$} & \multirow{2}{*}{0.328} \\
\hline & $\mathrm{GA}+\mathrm{GG}$ & 72 & 78 & & \\
\hline \multirow{2}{*}{ Dominant model } & $\mathrm{GA}+\mathrm{AA}$ & 82 & 76 & \multirow{2}{*}{$1.43(0.72-2.85)$} & \multirow{2}{*}{0.298} \\
\hline & GG & 18 & 24 & & \\
\hline \multirow{2}{*}{ Codominant model } & GA & 54 & 54 & \multirow{2}{*}{$1.00(0.57-1.74)$} & \multirow{2}{*}{1.000} \\
\hline & $\mathrm{GG}+\mathrm{AA}$ & 46 & 46 & & \\
\hline \multicolumn{6}{|l|}{ Allele } \\
\hline G & & $90(45 \%)$ & $102(51 \%)$ & \multirow{2}{*}{$1.27(0.85-1.88)$} & \multirow{2}{*}{0.230} \\
\hline A & & $110(55 \%)$ & $98(49 \%)$ & & \\
\hline
\end{tabular}

OR: odds ratio, CI: confidence interval, and $n$ : number in sample. * Significant at $p<0.05$.

TABLE 8: Genotype distribution of -844G/A polymorphism for AMI and CSA.

\begin{tabular}{lccc}
\hline Genotype & $\begin{array}{c}\text { Group I (AMI) } \\
(n=100)\end{array}$ & $\begin{array}{c}\text { Group II (CSA) } \\
(n=100)\end{array}$ & $\begin{array}{c}p \\
\text { value }\end{array}$ \\
\hline GG & $20(20 \%)$ & $18(18 \%)$ & \\
GA & $56(56 \%)$ & $54(54 \%)$ & 0.798 \\
AA & $24(24 \%)$ & $28(28 \%)$ & \\
\hline
\end{tabular}

*Significant at $p<0.05$.

TABLE 9: Comparison of PAI level (ng/ml) according to 4G/5G and -844G/A polymorphism in the AMI cases and control groups.

\begin{tabular}{|c|c|c|c|c|c|}
\hline \multirow[b]{2}{*}{ Genotype } & \multicolumn{2}{|r|}{ AMI } & \multicolumn{2}{|c|}{ Control } & \multirow[b]{2}{*}{$p$ value } \\
\hline & Number & Mean (SD) & Number & $\begin{array}{c}\text { Mean } \\
(\mathrm{SD})\end{array}$ & \\
\hline $4 \mathrm{G} / 4 \mathrm{G}$ & 31 & $28.62(8.57)$ & 20 & $\begin{array}{l}23.04 \\
(7.23)\end{array}$ & $0.019^{*}$ \\
\hline $4 \mathrm{G} / 5 \mathrm{G}$ & 59 & $28.40(8.38)$ & 38 & $\begin{array}{l}22.94 \\
(7.20)\end{array}$ & $0.001^{*}$ \\
\hline $5 \mathrm{G} / 5 \mathrm{G}$ & 10 & $25.63(11.41)$ & 42 & $\begin{array}{l}22.93 \\
(7.21)\end{array}$ & 0.349 \\
\hline GG & 20 & $25.43(11.15)$ & 24 & $\begin{array}{l}22.71 \\
(7.33)\end{array}$ & 0.337 \\
\hline GA & 56 & $28.12(8.21)$ & 54 & $\begin{array}{l}23.11 \\
(7.08)\end{array}$ & $0.0009^{*}$ \\
\hline $\mathrm{AA}$ & 24 & $28.62(8.57)$ & 22 & $\begin{array}{l}23.04 \\
(7.23)\end{array}$ & $0.022^{*}$ \\
\hline
\end{tabular}

*Significant at $p<0.05$.

to obtain significant difference in the presence of CAD in hypertensive and nonhypertensive participants and more, so results showed higher incidence of $\mathrm{CAD}$ in nondiabetic participants $[11,12]$. We also found AMI and CSA to be more often in individuals who smoke and consume alcohol and this is in congruence with previous studies [13, 14]. Advancing age and male gender are the most important known risk factors for ACS; similarly, the most common risk factor in our study was male gender followed by hypertension, nonvegetarian dietary habit, smoking, diabetes, alcohol intake, and family history of CAD [15]. Dyslipidemia includes raised LDL and TG, and low HDL poses risk to
Table 10: Comparison of PAI level (ng/ml) according to $4 \mathrm{G} / 5 \mathrm{G}$ and $-844 \mathrm{G} / \mathrm{A}$ polymorphism in the CSA cases and control groups.

\begin{tabular}{|c|c|c|c|c|c|}
\hline \multirow[b]{2}{*}{ Genotype } & \multicolumn{2}{|c|}{ CSA } & \multicolumn{2}{|c|}{ Control } & \multirow[b]{2}{*}{$p$ value } \\
\hline & Number & $\begin{array}{c}\text { Mean } \\
(\mathrm{SD})\end{array}$ & Number & Mean (SD) & \\
\hline $4 \mathrm{G} / 4 \mathrm{G}$ & 32 & $\begin{array}{l}30.04 \\
(8.32)\end{array}$ & 20 & $\begin{array}{l}23.04 \\
(7.23)\end{array}$ & $0.003^{*}$ \\
\hline $4 \mathrm{G} / 5 \mathrm{G}$ & 36 & $\begin{array}{l}30.33 \\
(7.57)\end{array}$ & 38 & $\begin{array}{l}22.94 \\
(7.20)\end{array}$ & $0.0001^{*}$ \\
\hline $5 \mathrm{G} / 5 \mathrm{G}$ & 32 & $\begin{array}{l}29.56 \\
(8.08)\end{array}$ & 42 & $22.93(7.21)$ & $0.0004^{*}$ \\
\hline GG & 18 & $\begin{array}{l}26.48 \\
(9.51)\end{array}$ & 24 & $22.71(7.33)$ & 0.154 \\
\hline GA & 54 & $\begin{array}{l}30.21 \\
(7.54)\end{array}$ & 54 & $23.11(7.08)$ & $<0.0001^{*}$ \\
\hline AA & 28 & $\begin{array}{l}30.04 \\
(8.32) \\
\end{array}$ & 22 & $\begin{array}{l}23.04 \\
(7.23) \\
\end{array}$ & $0.003^{*}$ \\
\hline
\end{tabular}

${ }^{*}$ Significant at $p<0.05$.

development of CAD; we, in the same way, documented significantly increased level of serum LDL and total cholesterol and low level serum HDL in patients with CSA and AMI with respect to control subjects [16-18]. The PAI-1 works to modulate the development of atherosclerosis and alter fibrinolysis. Thus, under the condition of impaired fibrinolysis, plaque rupture results in immediate formation of occlusive thrombus, leading to AMI, whereas normal or accelerated fibrinolysis prevents the formation of thrombus over ruptured atherosclerotic plaque and hence promotes the stenotic coronary lesions without precipitating thrombosis. Several studies have demonstrated the relationship of -844G/A polymorphism and PAI-1 levels with A allele and AA genotype being associated with raised level of PAI-1 protein and mRNA. We have also noted the raised PAI-1 level in individuals carrying -844GA or -844AA genotypes with higher levels in persons with higher load of A allele in all the three groups [19-21]. Few studies, as our study could not find any significant evidence to support the role of $-844 \mathrm{G} / \mathrm{A}$ polymorphism in AMI and CSA [22]. In contrast to that, some studies have shown association of $-844 \mathrm{G} / \mathrm{A}$ 
polymorphism and increased risk of CAD and AMI [19-23]. Although the association of AMI with the presence of $4 \mathrm{G}$ allele is controversial, many studies favor [23-29] and some disregard their involvement [30-32]. In our study, frequency of $4 \mathrm{G} / 4 \mathrm{G}$ and $4 \mathrm{G} / 5 \mathrm{G}$ genotype in AMI cases was significantly higher than controls. Thus, the presence of $4 \mathrm{G}$ allele does increase the risk of acute thrombosis and it has a similar reflection in terms of raised PAI-1 level with respect to the number of $4 \mathrm{G}$ alleles in a particular genotype. In subgroup analysis for mean plasma PAI-1 level, the PAI-1 level was significantly raised in both AMI and CSA with respect to control. CSA does not signify thrombosis; nevertheless, the level of PAI-1 was higher in CSA as compared to AMI, although not up to that significant level. This may be attributable to some of the genetic, environmental factors or other associated coronary risk factors such as insulin resistance, apart from $4 \mathrm{G} / 5 \mathrm{G}$ or $-844 \mathrm{GA}$ polymorphisms. We also performed subgroup analysis in diabetic and nondiabetic individuals to find out the PAI-1 level in these subgroups and the level was significantly elevated in diabetic patients as compared to nondiabetics, similar to previously conducted studies [33]. This present study is the first one to show significant association between $4 \mathrm{G} / 5 \mathrm{G}$ allele polymorphism and risk of AMI in Indian population, suggesting the potential role of this polymorphism in development of AMI.

There were some limitations in the present study. Firstly, the sample size was small. Indian population is thought to be most diverse due to different sociocultural traditions. A single larger study with diverse sample size may help us in better understanding the association of the genetic variation of these genes with AMI and CSA risk. Further studies on larger sample size are needed to confirm our findings.

\section{Conclusion}

Along with the traditional risk factors, the $4 \mathrm{G} / 5 \mathrm{G}$ allele polymorphism is an independent risk factor for the development of AMI. The detection of $4 \mathrm{G} / 5 \mathrm{G}$ allele may therefore be helpful in primary prevention. Patients who carry the 4G/ $5 \mathrm{G}$ allele polymorphism have high concentrations of PAI-1, which might be involved in incidents leading to AMI. This current study for the first time revealed significant association of $4 \mathrm{G} / 5 \mathrm{G}$ allele polymorphism with high risk of $\mathrm{AMI}$ in Indian population and will be helpful in identifying the genetic risk factors associated with AMI and CSA and for better management of diagnostic measures.

\section{Abbreviations}

AMI: $\quad$ Acute myocardial infarction

CSA: Chronic stable angina

PAI-1: Plasminogen activator inhibitor-1

CAD: $\quad$ Coronary artery disease

USA: Unstable angina

PCR- Polymerase chain reaction-restriction fragment

RFLP: length polymorphism

ACC: American College Cardiology

AHA: American Heart Association $\begin{array}{ll}\text { OR: } & \text { Odds ratio } \\ \text { CI: } & \text { Confidence interval. }\end{array}$

\section{Data Availability}

Data may be restricted in order to protect patient privacy. It can be obtained from the corresponding author on request only after institution approval.

\section{Additional Points}

(i) There is positive association of $4 \mathrm{G} / 5 \mathrm{G}$ and $-844 \mathrm{G} / \mathrm{A}$ polymorphisms with increased level of PAI-1 in patients with CSA and AMI. (ii) -844G/A polymorphism failed to show any significant association with the risk of development of AMI and CSA. (iii) There is significant association of 4G/5G polymorphism with increased AMI risk. (iv) This study will be helpful in identifying the genetic risk factors associated with AMI and CSA in a population.

\section{Ethical Approval}

The institutional board of AIIMS provided ethical clearance (Ref.No.IESC/T-252/03.06.2011) for the study.

\section{Consent}

Written informed consent was obtained from all patients and controls.

\section{Disclosure}

Sunil Kumar is a co-first author.

\section{Conflicts of Interest}

The authors declare no conflicts of interest.

\section{Authors' Contributions}

Conceptualization was performed by RS and RY. Data curation was performed by SK, PT, and RR. Formal analysis was carried out by AKV, DB, YG, and KD. Funding was acquired by RS and RY. Investigation was done by SK and RS. Methodology was performed by SK, RR, and RS. Project administration was performed by RS, RY, and SK. Resources were presented by RS, RY, and SK. Software was performed by AKV, DB, and KD. Supervision was done by RS. Validation was performed by RS and RY. Visualization was carried out by RS and RY. Roles/writing-original draft-was done by SK and AKV. Writing-review and editing-was performed by VS, AKV, DB, AHR, SAA, AA, $\mathrm{MAA}$, and $\mathrm{KD}$.

\section{Acknowledgments}

The authors would like to acknowledge all the study participants who were included in this study. SK would also like to acknowledge Department of Hematology, All India 
Institute of Medical Sciences, New Delhi, for providing infrastructure facilities for conducting research work.

\section{References}

[1] S. H. Wild and C. D. Byrne, "Risk factors for diabetes and coronary heart disease," BMJ, vol. 333, no. 7576, pp. 1009-1011, 2006.

[2] J. Hsu and J. D. Smith, "Genome-wide studies of gene expression relevant to coronary artery disease," Current Opinion in Cardiology, vol. 27, no. 3, pp. 210-213, 2012.

[3] D. E. Vaughan, "PAI-1 and atherothrombosis," Journal of Thrombosis and Haemostasis, vol. 3, no. 8, pp. 1879-1883, 2005.

[4] M. T. Sartori, C. Danesin, G. Saggiorato et al., "The PAI-I gene $4 \mathrm{G} / 5 \mathrm{G}$ polymorphism and deep vein thrombosis in patients with inherited thrombophilia," Clinical and Applied Thrombosis/Hemostasis, vol. 9, no. 4, pp. 299-307, 2003.

[5] P. Eriksson, B. Kallin, F. M. v. Hooft, P. Båvenholm, and A. Hamsten, "Allele-specific increase in basal transcription of the plasminogen-activator inhibitor 1 gene is associated with myocardial infarction," Proceedings of the National Academy of Sciences, vol. 92, no. 6, pp. 1851-1855, 1995.

[6] B. Zöller, P. G. d. Frutos, and B. Dahlbäck, "A common 4G allele in the promoter of the plasminogen activator inhibitor-1 (PAI-1) gene as a risk factor for pulmonary embolism and arterial thrombosis in hereditary protein S deficiency," Thrombosis and Haemostasis, vol. 79, no. 4, pp. 802-807, 1998.

[7] R. Junker, D. G. Nabavi, E. Wolff et al., "Plasminogen activator inhibitor-1 4G/4G-genotype is associated with cerebral sinus thrombosis in factor V leiden carriers," Thrombosis and Haemostasis, vol. 80, pp. 706-707, 1998.

[8] D. Tàssies, G. Espinosa, F. J. Muñoz-Rodríguez et al., “The 4G/ $5 \mathrm{G}$ polymorphism of the type 1 plasminogen activator inhibitor gene and thrombosis in patients with antiphospholipid syndrome," Arthritis \& Rheumatism, vol. 43, no. 10, pp. 2349-2358, 2000.

[9] T. J. Key, G. E. Fraser, M. Thorogood et al., "Mortality in vegetarians and nonvegetarians: detailed findings from a collaborative analysis of 5 prospective studies," American Journal of Clinical Nutrition, vol. 70, pp. 516S-524S, 1999.

[10] K. Shridhar, P. K. Dhillon, L. Bowen et al., "The association between a vegetarian diet and cardiovascular disease (CVD) risk factors in India: the Indian migration study," PLoS One, vol. 9, no. 10, Article ID e110586, 2014.

[11] C. M. M. Lawes, D. A. Bennett, S. Lewington, and A. Rodgers, "Blood pressure and coronary heart disease: a review of the evidence," Seminars in Vascular Medicine, vol. 2, no. 4, pp. 355-368, 2002.

[12] S. M. Grundy, I. J. Benjamin, G. L. Burke et al., "Diabetes and cardiovascular disease," Circulation, vol. 100, no. 10, pp. 1134-1146, 1999.

[13] I. S. Ockene and N. H. Miller, "Cigarette smoking, cardiovascular disease, and stroke," Circulation, vol. 96, no. 9, pp. 3243-3247, 1997.

[14] T. A. Pearson, "Alcohol and heart disease," Circulation, vol. 94, no. 11, pp. 3023-3025, 1996.

[15] A. García-Castillo, C. Jerjes-Sánchez, P. MartínezBermúdez et al., "RENASICA II. Mexican registry of acute coronary syndromes," Arch CardiolMex, vol. 75, no. S1, pp. S6-S32, 2005.

[16] S. M. Rubin, S. Sidney, D. M. Black, W. S. Browner, S. B. Hulley, and S. R. Cummings, "High blood cholesterol in elderly men and the excess risk for coronary heart disease,"
Annals of Internal Medicine, vol. 113, no. 12, pp. 916-920, 1990.

[17] P. H. Frost, B. R. Davis, A. J. Burlando et al., "Serum lipids and incidence of coronary heart disease," Circulation, vol. 94, no. 10, pp. 2381-2388, 1996.

[18] S. Houterman, W. M. M. Verschuren, A. Hofman, and J. C. M. Witteman, "Serum cholesterol is a risk factor for myocardial infarction in elderly men and women: the rotterdam study," Journal of Internal Medicine, vol. 246, no. 1, pp. 25-33, 1999.

[19] P. E. Morange, N. Saut, M. C. Alessi et al., "Association of plasminogen activator inhibitor (PAI)-1 (SERPINE1) SNPs with myocardial infarction, plasma PAI-1, and metabolic parameters," Arteriosclerosis, Thrombosis, and Vascular Biology, vol. 27, no. 10, pp. 2250-2257, 2007.

[20] M. Henry, D. A. Tregouët, M. C. Alessi et al., "Metabolic determinants are much more important than genetic polymorphisms in determining the PAI-1 activity and antigen plasma concentrations," Arteriosclerosis, Thrombosis, and Vascular Biology, vol. 18, no. 1, pp. 84-91, 1998.

[21] N. M. Torres-Carrillo, N. Torres-Carrillo, M. Vázquez-Del Mercado et al., "The - 844 G/A PAI-1 polymorphism is associated with mRNA expression in rheumatoid arthritis," Rheumatology International, vol. 28, no. 4, pp. 355-360, 2008.

[22] L. Fu, H. Jin, K. Song, C. Zhang, J. Shen, and Y. Huang, "Relationship between gene polymorphism of the PAI-1 promoter and myocardial infarction," Chinese Medical Journal, vol. 114, pp. 266-269, 2001.

[23] N. Abboud, L. Ghazouani, S. Saidi et al., "Association of PAI-1 $4 \mathrm{G} / 5 \mathrm{G}$ and $-844 \mathrm{G} / \mathrm{A}$ gene polymorphisms and changes in PAI-1/tissue plasminogen activator levels in myocardial infarction: a case-control study," Genetic Testing and Molecular Biomarkers, vol. 14, no. 1, pp. 23-27, 2010.

[24] N. Iwai, H. Shimoike, Y. Nakamura, S. Tamaki, and M. Kinoshita, "The $4 \mathrm{G} / 5 \mathrm{G}$ polymorphism of the plasminogen activator inhibitor gene is associated with the time course of progression to acute coronary syndromes," Atherosclerosis, vol. 136, no. 1, pp. 109-114, 1998.

[25] M. Margaglione, G. Cappucci, D. Colaizzo et al., "The PAI-1 gene locus $4 \mathrm{G} / 5 \mathrm{G}$ polymorphism is associated with a family history of coronary artery disease," Arteriosclerosis, Thrombosis, and Vascular Biology, vol. 18, no. 2, pp. 152-156, 1998.

[26] T. Pastinen, M. Perola, P. Niini et al., "Array-based multiplex analysis of candidate genes reveals two independent and additive genetic risk factors for myocardial infarction in the finnish population," Human Molecular Genetics, vol. 7, no. 9, pp. 1453-1462, 1998.

[27] S. Grancha, A. Estellés, G. Tormo et al., "Plasminogen activator inhibitor-1 (PAI-1) promoter 4G/5G genotype and increased PAI-1 circulating levels in postmenopausal women with coronary artery disease," Thrombosis and Haemostasis, vol. 81, no. 4, pp. 516-521, 1999.

[28] A. Gardemann, J. Lohre, N. Katz, H. Tillmanns, F. W. Hehrlein, and W. Haberbosch, "The 4G4G genotype of the plasminogen activator inhibitor $4 \mathrm{G} / 5 \mathrm{G}$ gene polymorphism is associated with coronary atherosclerosis in patients at high risk for this disease," Thrombosis and Haemostasis, vol. 82, pp. 1121-1126, 1999.

[29] J. Mikkelsson, M. Perola, U. Wartiovaara et al., "Plasminogen activator inhibitor-1 (PAI-1) 4G/5G polymorphism, coronary thrombosis, and myocardial infarction in middle-aged finnish men who died suddenly," Thrombosis and Haemostasis, vol. 84, pp. 78-82, 2000. 
[30] J. L. Anderson, J. B. Muhlestein, J. Habashi et al., "Lack of association of a common polymorphism of the plasminogen activator inhibitor-1 gene with coronary artery disease and myocardial infarction," Journal of the American College of Cardiology, vol. 34, no. 6, pp. 1778-1783, 1999.

[31] C. J. M. Doggen, R. M. Bertina, V. M. Cats, P. H. Reitsma, and F. R. Rosendaal, "The $4 \mathrm{G} / 5 \mathrm{G}$ polymorphism in the plasminogen activator inhibitor-1 gene is not associated with myocardial infarction," Thrombosis and Haemostasis, vol. 82, no. 7, pp. 115-120, 1999 .

[32] I. Canavy, M. Henry, P. E. Morange et al., "Genetic polymorphisms and coronary artery disease in the south of France," Thrombosis and Haemostasis, vol. 83, no. 2, pp. 212-216, 2000.

[33] R. P. Gray, J. S. Yudkin, and D. L. Patterson, "Plasminogen activator inhibitor: a risk factor for myocardial infarction in diabetic patients," Heart, vol. 69, no. 3, pp. 228-232, 1993. 